\title{
Acute Chest Syndrome in Sickle Cell Disease Patients Post Caesarean Delivery
}

\author{
YM Zhang ${ }^{1,2,3}$, N France1, L Evans ${ }^{1,4}$, JL Gao ${ }^{2,3,5}$
}

\begin{abstract}
Sickle cell disease (SCD) is the most common inherited disease worldwide and is associated with anaemia and intermittent painful crisis. Pregnant women who are affected are known to have increased maternal and fetal mortality and morbidity. Acute chest syndrome (ACS) is an uncommon but serious complication in pregnant women with SCD that can lead to death. We present two cases of patients with $S C D$, both of whom had severe ACS within 24 hours post Caesarean section. By accurate diagnosis and appropriate management by a multidisciplinary team, both mothers and fetuses had excellent outcomes. It is suggested that prompt recognition of ACS in a pregnant woman with SCD and collaborative medical and obstetric management are essential to optimize maternal and fetal outcomes.
\end{abstract}

Keywords: Acute chest syndrome, Caesarean delivery, high risk pregnancy, intensive care, sickle cell disease

WIMJ Open 2016; 3 (1): 21

\section{INTRODUCTION}

Sickle cell disease (SCD) is a common autosomal recessive haemoglobinopathy, which affects about 270 million heterozygote carriers worldwide. Sickle cell disease typically presents with repetitive sickling crises. Acute chest syndrome (ACS) is a vaso-occlusive crisis of the pulmonary vasculature in patients with SCD (1). Acute chest syndrome is most commonly triggered by infections, dehydration and acidosis $(2,3)$; however, pregnancy and surgery can exacerbate ACS, leading to this complication as well $(3,4)$. We present two cases of severe ACS in patients with SCD post Caesarean delivery, both of whom developed severe ACS within 24 hours post Caesarean section. Both had excellent maternal-fetal outcome after prompt recognition and multidiscipline intervention.

\section{CASE REPORTS}

\section{Case 1}

A 28-year old woman, gravida 1 , para $0\left(\mathrm{G}^{1} \mathrm{P}^{0}\right)$, gestational age 31 weeks +3 days of mixed ethnicity (Black and East Indian) with known SCD and no prior history of ACS was referred to our department with a one-day history of back

From: ${ }^{1}$ Department of Obstetrics and Gynaecology, Georgetown Public Hospital Corporation, Georgetown, Guyana, ${ }^{2}$ China Medical Team, ${ }^{3}$ The First Affiliated Hospital of Soochow University, Suzhou, Jiangsu, China, ${ }^{4}$ WONDOOR Fellow, University Hospital, Case Western Reserve University, Cleveland, Ohio, USA and ${ }^{5}$ Intensive Care Unit, Georgetown Public Hospital Corporation, Georgetown, Guyana.

Correspondence: Dr YM Zhang, Georgetown Public Hospital, New Market Street, Georgetown, Guyana. E-mail: zyueming7001@hotmail.com pain, joint pain and chest pain. She recognized her symptoms as a crisis, as she had previous episodes, the most recent being five years ago. Other pertinent past medical and surgical history was that of cholecystectomy three years prior. On admission, her vital signs were all within normal ranges. She was admitted and placed on oxygen therapy, was rehydrated and received analgesia and corticosteroids for fetal lung maturity. Initial investigations revealed haemoglobin $(\mathrm{Hb}) 5.0 \mathrm{~g} / \mathrm{dL}$, white blood cell (WBC) $20 \mathrm{x}$ $10^{9} / \mathrm{L}$, neutrophils $86 \%$, lymphocytes $14 \%$, platelet (Plt) 532 $000 / \mathrm{mm}^{3}$, total bilirubin (TBil) $4.9 \mathrm{mg} / \mathrm{dL}$ and direct bilirubin (DBil) $3.1 \mathrm{mg} / \mathrm{dL}$. Sickling test was positive (hooks method). Renal function and electrolytes were all within normal ranges. She was transfused one unit of packed red blood cells (RBCs). Later that day, she com-plained of headaches and vital signs revealed an elevated blood pressure of 170/110 $\mathrm{mmHg}$ and $2+$ urine protein on dipstick. She was diagnosed with new-onset severe pre-eclampsia, and started on antihypertensives: methyldopa $500 \mathrm{mg}$, three times a day, ahydralazine $5 \mathrm{mg}$ intravenously, $P R N$. Intravenous magnesium sulfate loading dose was given, followed by maintenance doses; prophylactic ceftriaxone was also commenced. She was managed expectantly on the ward for a week with daily non-stress test (NST) and weekly biophysical profile (BPP) for severe pre-eclampsia and sickle cell crisis. Her chest and joint pains improved significantly but her pre-eclampsia laboratory values showed worsening disease: $\mathrm{Hb} 8.0 \mathrm{~g} / \mathrm{dL}$, Plt $128000 / \mathrm{mm}^{3}$, creatinine $(\mathrm{Cr}) 1.0$ $\mathrm{mg} / \mathrm{dL}$, aspartate transaminase (AST) $139 \mathrm{U} / \mathrm{L}$ and alanine transaminase (ALT) $61 \mathrm{U} / \mathrm{L}$. The decision was made for 
delivery via Caesarean section on account of worsening preeclampsia prior to 34 weeks gestational age and breech presentation of the fetus. Caesarean delivery was done under spinal anaesthesia on day eight of admission $(32+4$ weeks $)$ and a live female neonate weighing $2020 \mathrm{~g}$ with Apgar scores of 9 and 10 at one and five minutes, respectively was determined. Intraoperative blood loss was $250 \mathrm{~mL}$.

Postoperatively, her $\mathrm{Hb}$ was $6.0 \mathrm{~g} / \mathrm{dL}$ and she had one unit of packed RBCs transfused. She was noted to have arterial blood oxygen saturation $\left(\mathrm{SpO}_{2}\right)$ values of $95-96 \%$ on room air, but this improved with oxygen therapy via face mask. Approximately 24 hours postoperatively, she complained of increasing chest pains and shortness of breath; her oxygen saturation dropped to $90 \%$ with continuous oxygen therapy and she was transferred to the intensive care unit (ICU). Initial arterial blood gas (ABG) revealed partial pressure of carbon dioxide $\left(\mathrm{PCO}_{2}\right): 25 \%$, partial pressure of oxygen $\left(\mathrm{PO}_{2}\right): 69 \%$, base excess $(\mathrm{BE})-8 \mathrm{mmol} / \mathrm{L}$, bicarbonate $\left(\mathrm{HCO}_{3}\right) 16.6 \mathrm{mEq} / \mathrm{L}$, oxygen saturation $\left(\mathrm{SO}_{2}\right)$ $94 \%$ and total carbon dioxide $\left(\mathrm{TCO}_{2}\right) 17 \mathrm{mmol} / \mathrm{L}$. She was intubated and placed on mechanical ventilation. Chest X-ray revealed bilateral infiltrates in the lung fields (Figure). She also had a fever and a lung infection was suspected, thus vancomycin was added to her antibiotic therapy. She remained intubated and on mechanical ventilation for five days. Further management of her ACS involved one additional unit of packed $\mathrm{RBC}$ and four units fresh frozen plasma (FFP), oral antihypertensive and chest physiotherapy. Her WBC count improved and she made a full recovery from her ACS. After 18 days of hospital admission, she was discharged. Electrophoresis results drawn before discharge revealed $\mathrm{HbA}: 30.3 \%$, $\mathrm{HbF}: 9.3 \%$ and $\mathrm{HbS}: 58.4 \%$.

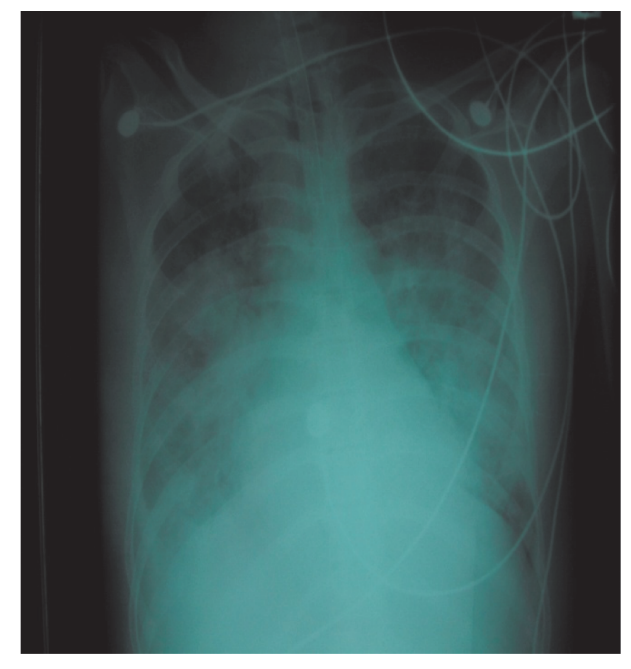

Figure: Chest X-ray showing bilateral infiltrates in the lung fields of Case 1.

\section{Case 2}

A 28-year old female, $\mathrm{G}^{1} \mathrm{P}^{0}$ of mixed ethnicity with known SCD was admitted to our obstetric department at GA $35+2$ weeks for severe intrauterine growth restriction (IUGR) and oligohydramnios. She was a member of our clinic since 11 weeks gestational age and showed signs of IUGR starting at 24 weeks gestational age. She had one previous admission at $31+6$ weeks for back pain at which time she was given analgesics and discharged. Her last sickle cell crisis was five years prior to her pregnancy and she had received a total of seven blood transfusions in her life, the last at three years of age.

On admission, all vitals were within normal ranges. Her laboratory results on admission were noted to be: $\mathrm{Hb} 8.0$ $\mathrm{g} / \mathrm{dL}, \mathrm{Cr} 0.7 \mathrm{mg} / \mathrm{dL}$, blood urea nitrogen (BUN) $10 \mathrm{mg} / \mathrm{dL}$, DBil $1.8 \mathrm{mg} / \mathrm{dL}$, TBil $4.4 \mathrm{mg} / \mathrm{dL}$, AST $59 \mathrm{U} / \mathrm{L}$, ALT $34 \mathrm{U} / \mathrm{L}$. She had one unit RBC transfused. On day four of admission, while receiving a routine antenatal fetal tracing, the patient was found to have repetitive late decelerations. She subsequently had an emergency Caesarean delivery at gestational age $35+6$ weeks on account of suspected fetal distress. A live male neonate with Apgar scores of 9 and 10, at one and five minutes, respectively was delivered. Intraoperative blood loss was $350 \mathrm{~mL}$ and she had one more unit RBC transfused postoperatively. At 12 hours post Caesarean section, she presented with tachycardia and tachypnoea. Vital signs were the following: heart rate: 120 bpm, respiratory rate: $40 / \mathrm{m}$, blood pressure $114 / 78 \mathrm{mmHg}$, $\mathrm{SpO}_{2} 92 \%$. On examination, the patient was found to have crepitations bilaterally in both lung fields. She was given nebulizer treatments and observed closely in the ICU with multidisciplinary management by internal medicine, obstetrics and the ICU team. Imaging done in ICU included a chest X-ray showing bilateral infiltrates in both lung fields. Her condition initially improved; however, 26 hours postoperatively, the patient decompensated and was intubated and placed on mechanical ventilation. At this point, her $\mathrm{ABG}$ results were: $\mathrm{pH} 7.34, \mathrm{BE} 13 \mathrm{mmol} / \mathrm{L}, \mathrm{PCO}_{2} 22.7 \mathrm{mmHg}$, $\mathrm{HCO}_{3}^{-} 12.3 \mathrm{mEq} / \mathrm{L}, \mathrm{PO}_{2} 52 \mathrm{mmHg}, \mathrm{TCO}_{2} 13 \mathrm{mmol} / \mathrm{L}$. She was managed with hydration, sodium bicarbonate, hydrocortisone, ceftriaxone, vancomycin and heparin. She showed steady improvement on ventilatory support and on day 10 she was extubated. On day one post-extubation she complained of shortness of breath; she was nebulized and her condition improved. On day two post-extubation, she showed signs of respiratory distress with bilateral crepitations. She was reintubated for seven days, until pulmonary status improved enough to eventually extubate. After 27 days of hospitalization, the patient was discharged. Postpartum evaluation revealed mother and infant both doing well with no signs of ongoing maternal pulmonary complications.

\section{DISCUSSION}

Pregnancies complicated by SCD are at increased risk of pyelonephritis, pulmonary infarction, pneumonia, preterm premature rupture of membranes, intrauterine growth restriction, low birth weight and prematurity. An increased risk of pre-eclampsia and gestational hypertension has been shown in both large retrospective studies and smaller 
observational studies $(5,6)$. Nonetheless, advances in general medical care, transfusion medicine, prenatal sur-veillance and neonatology have improved the mortality associated with SCD and pregnancy. Thus, obstetrics and neonatology experts do not discourage women with SCD from attempting pregnancy $(7,8)$. Upon reviewing the literature, we found limited data from underdeveloped countries with limited resources on management of SCD in pregnancy. In the two cases presented here, complications occurred in the third trimester and new onset ACS happened post Caesarean delivery. Case one had a painful crisis and severe preeclampsia and subsequently had Caesarean section; case two developed IUGR and oligohydraminos and eventually had Caesarean section due to fetal distress.

The mortality rate for women with SCD is 72.4 deaths per 100000 deliveries, compared with a mortality rate of 12.7 deaths per 100000 deliveries for women without SCD (2). Most deaths in pregnant women with SCD are attributable to thromboembolic events (7). Acute chest syndrome, although uncommon during pregnancy, is another important cause $(3,9)$.

Acute chest syndrome is defined as the presence of a new pulmonary infiltrate with one or more symptoms, such as fever, cough, sputum production, tachypnoea, dyspnoea, or new-onset hypoxia. Acute chest syndrome is a severe pulmonary complication in pregnant women with SCD and is seen in $7-20 \%$ of pregnancies $(5,10)$. The exact pathophysiology of ACS is uncertain; the aetiology of its associated respiratory compromise is multifactorial $(11,12)$. Acute chest syndrome has been attributed to direct consequences of $\mathrm{HbS}$ such as pulmonary vaso-occlusion, fat emboli from bone marrow infarctions, and subsequent hypoventilation. Infectious aetiologies have also been implicated (3). Furthermore, ACS appears to be associated with other pathological processes, such as aspiration, trauma, asthma and iatrogenic causes. Upon reviewing the literature, we were not able to find any ACS case which was thought to have been triggered by Caesarean delivery.

Acute chest syndrome is characterized by a new infiltrate on chest $\mathrm{X}$-ray in association with respiratory signs and symptoms. It is difficult to distinguish from pneumonia, and can co-exist with infection (1). Hypoxia is an early sign of acute chest syndrome. The differential diagnosis of ACS is pulmonary embolism (3), which is also more common in pregnancy in women with SCD. This diagnosis should be considered in women presenting with chest pain and hypoxia, especially if chest X-ray is normal. Both patients had emergency Caesarean section secondary to obstetric indications, thus the immediate preoperative physical examination was limited. Both patients, however, had a normal pulmonary examination with no respiratory symptoms prior to Caesarean section. In addition, normal oxygen saturation was detected before and during the Caesarean delivery. Twentyfour hours after the deliveries, both patients complained of shortness of breath and severe hypoxia, confirmed by ABG. Based on these findings, the diagnosis of ACS was made in each of these patients.

Treatment of ACS entails antibiotics, supplemental oxygen, analgesics, hydration, and either simple or exchange RBC transfusions (5). Simple RBC transfusions may increase oxygen-carrying capacity but can also increase blood viscosity, which may promote further sickling. Exchange transfusions replace sickled RBCs with normal RBCs without altering blood viscosity and, consequently, improve delivery of oxygen to oxygen-deprived tissues. The decision for simple or exchange transfusion ideally should depend on the severity of the situation $(6,13)$. Exchange transfusion is recommended in the treatment of severe complications such as ACS, stroke and multi-organ failure in patients with SCD. Our two cases both had ACS, but as they were cared for in a resource-poor setting, exchange transfusion was not available for their treatment. Simple transfusion was therefore performed under close monitoring. The patients were transfused with a goal haemoglobin of $8 \mathrm{~g} / \mathrm{dL}$, and after reaching that point, blood transfusion was strictly limited in order to prevent increased blood viscosity, which may promote further sickling.

Supplemental oxygen for drop in pulse oximetry by $4 \%$ over baseline, or values $<92 \%$ is advised (12). Continued respiratory therapy is also recommended, and bronchodilators for patients with reactive airway disease should be considered (12). Mechanical ventilation is another key to success which was able to be provided in these two cases.

There are no randomized controlled trials providing evidence about optimal timing of delivery. Once women reach 38 weeks gestation, they should be monitored weekly, and if there are any signs of maternal or fetal complications eg hypertension, proteinuria or poor fetal growth, delivery should be considered (5). Most women will go into spontaneous labour, and vaginal delivery is the recommended mode of delivery. Indications for Caesarean section should be based on the usual obstetric indications (2), and acute painful crisis does not constitute an indication (5). In the cases we present, one was delivered at 32 weeks 4 days gestational age because of worsening severe pre-eclampsia (obstetric indication). The second was delivered at 35 weeks and 6 days gestational age due to fetal distress.

Prophylactic transfusion before a Caesarean delivery to avoid precipitating a crisis due to blood loss is not only acceptable but encouraged in patients with haemoglobin 7 to $8 \mathrm{~g} / \mathrm{dL}$ or less, which was done in the cases presented here. Since ACS may occur as a postoperative complication in patients with SCD, especially following abdominal surgery $(4,14)$, vaginal delivery is preferred over Caesarean delivery when possible.

Although most women typically know their diagnosis of sickle cell disorder before their pregnancy, a definitive diagnosis or confirmation and characterization by haemoglo- 
bin electrophoresis is required. Both of our patients presented with known diagnosis of SCD.

\section{REFERENCES}

1. Vichinsky EP, Neumayr LD, Earles AN, Williams R, Lennette ET, Dean $\mathrm{D}$ et al. Causes and outcomes of the acute chest syndrome in sickle cell disease. National Acute Chest Syndrome Study Group. N Engl J Med 2000; 342: 1855-65.

2. Villers MS, Jamison MG, De Castro LM, James AH. Morbidity associated with sickle cell disease in pregnancy. Am J Obstet Gynecol 2008; 199: 125.e1-5.

3. Paul RN, Castro OL, Aggarwal A, Oneal PA. Acute chest syndrome: sickle cell disease. Eur J Haematol 2011; 87: 191-207. doi: 10.1111/j.1600-0609.2011.01647.x. Epub 2011 Jul 26.

4. Adam S, Jonassaint J, Kruger H, Kail M, Orringer EP, Eckman JR et al Surgical and obstetric outcomes in adults with sickle cell disease. Am J Med 2008; 121: 916-21.

5. Howard J, Oteng-Ntim E. The obstetric management of sickle cell disease. Best Pract Res Clin Obstet Gynaecol 2012; 26: 25-36. doi: 10.1016/j.bpobgyn.2011.10.001. Epub 2011 Nov 22.

6. Al Kahtani MA, AlQahtani M, Alshebaily MM, Abd Elzaher M, Moawad A, Aljohani N. Morbidity and pregnancy outcomes associated with sickle cell anemia among Saudi women. Int J Gynaecol Obstet 2012; 119: 224-6. doi: 10.1016/j.ijgo.2012.07.008. Epub 2012 Sep 15.

7. Hassell K. Pregnancy and sickle cell disease. Hematol Oncol Clin North Am 2005; 19: 903-16.

8. ACOG Committee on Obstetrics. ACOG Practice Bulletin No. 78 hemoglobinopathies in pregnancy. Obstet Gynecol 2007; 109: 229-37.

9. Livesay S, Ruppert SD. Acute chest syndrome of sickle cell disease. Crit Care Nurs Q 2012; 35: 183-95. doi: 10.1097/CNQ. 0b013e3182456630.
10. Serjeant GR, Loy LL, Crowther M, Hambleton IR, Thame M. Outcome of pregnancy in homozygous sickle cell disease.Obstet Gynecol 2004; 103: $1278-85$.

11. Campbell K, Ali U, Bahtiyar M. Acute chest syndrome during pregnancy as initial presentation of sickle cell disease: a case report. Am J Perinatol 2008; 25: 547-9. doi: 10.1055/s-0028-1085628. Epub 2008 Aug 28.

12. Desai PC, Ataga KI. The acute chest syndrome of sickle cell disease. Expert Opin Pharmacother 2013; 14: 991-9. doi: 10.1517/ 14656566.2013.783570. Epub 2013 Mar 28.

13. Grossetti E, Carles G, El Guindi W, Seve B, Montoya Y, Creveuil C et al. Selective prophylactic transfusion in sickle cell disease. Acta Obstet Gynecol Scand 2009; 88: 1090-4. doi: 10.1080/00016340903134171.

14. Camous J, N'da A, Etienne-Julan M, Stéphan F. Anesthetic management of pregnant women with sickle cell disease - effect on postnatal sickling complications. Can J Anaesth 2008; 55: 276-83. doi: 10.1007/BF03017204.

Received 03 Aug 2015

Accepted 15 Sep 2015

Published 09 Feb 2016

Online: http://www.mona.uwi.edu/wimjopen/article/1662

(c) Zhang et al 2016.

This is an open access article made freely available under Creative Commons Attribution 4.0 International (CC BY 4.0). Users are free to share, copy and adapt this work as long as the copyright holder (author) is appropriately and correctly credited. See http://creativecommons.org/ licences/by/4.0/deed.en us for more information. 